\title{
CARACTERÍSTICAS FONÉTICAS E CONTRASTES FONOLÓGICOS EM DADOS DE FALA DE PESSOAS COM DOWN: PERSPECTIVA DA GEOMETRIA DE TRAÇOS ${ }^{1}$
}

\author{
PHONETIC AND PHONOLOGICAL CONTRASTS IN DATA OF THE PEOPLE WITH \\ DOWNS' SYNDROME: ANALYZING BY GEOMETRY OF PHONOLOGICAL FEATURE
}

\author{
Marian Oliveira (PPGLin-UESB) \\ Universidade Estadual do Sudoeste da Bahia \\ mdossoliveira@gmail.com \\ Vera Pacheco (PPGLin-UESB) \\ Universidade Estadual do Sudoeste da Bahia \\ vera.pacheco@gmail.com
}

\begin{abstract}
A fala da pessoa com Down se difere da fala de pessoas sem síndrome. Diante disso, questionamos se tal diferença é meramente auditiva ou se tem implicação para o sistema linguístico. Neste trabalho, objetivamos mostrar, através da análise do espaço vocálico, que oposições fonológicas são mantidas nos diferentes tipos silábicos e como, em termos acústicos, essas oposições são garantidas. $\mathrm{Na}$ análise acústica, pautamo-nos na Teoria Fonte-Filtro (Fant, 1960); na caracterização das vogais usamos a proposta de Matzenauer e Miranda. (2009). Foram analisados dados de 08 sujeitos, divididos em: 04 sujeitos com síndrome de Down e 04 sem síndrome, para fins de comparação; todos eles naturais e moradores de Vitória da Conquista/BA - Brasil, com faixa etária entre 17 e 21 anos de idade. A hipótese que sustenta a pesquisa é a de que as vogais produzidas por esses sujeitos apresentam características fonéticas diferenciadas, porém tais características não afetam o sistema linguístico que permanece preservado, isto é, as oposições fonológicas são mantidas.
\end{abstract}

Palavras chave: espaço vocálico; geometria vocálica; síndrome de Down.

Keywords: Down's syndrome; Vowel area; Vowel Geometry.

Abstract: The speech, in Down's syndrome population, is different, but is necessary to know if this difference is only phonetic or if it changes the linguistic system. This paper aims at analyzing the vocalic area in Down's syndrome and to show that phonological oppositions are maintained in the speech of people with DS, i.e. the difference in vocalic production in DS is only acousticarticulatory. The analyzing was conducted by Acoustic Theory of Speech Production (Fant, 1960) and by vowel geometry's proposal (Matzenauer and Miranda, 2009). In this research we analyze data of the 04 people with DS and 04 people without syndrome. Everybody was born and lives in Vitoria da Conquista, Bahia - Brazil, and have 17 or 21 years old. The research's hypothesis is the vowels produced by DS people are phonetically different but these differences don't change the phonological system.

(Recibido: 17/01/2016; Aceptado: 27/05/2016)

\footnotetext{
${ }^{1}$ O presente trabalho integra pesquisa apoiada pelo CNPq - Processo no 482187/2013-1.
} 


\section{Considerações iniciais}

Uma das questões mais problemáticas em torno da síndrome de Down (SD), alteração genética que gera hipotonia orofacial e macroglossia ou falsa macroglossia, diz respeito ao desenvolvimento das habilidades linguísticas. Foneticamente, a fala da pessoa com Down se difere da de pessoas sem a síndrome. Diante desse problema, uma das questões que se pode formular é se tal diferença é meramente auditiva ou se tem implicação para o sistema linguístico.

Em relação à produção vocálica, nossa hipótese de trabalho é a de que as vogais orais produzidas por esses sujeitos apresentam características fonéticas diferenciadas, conforme atestam os trabalhos sobre a produção vocálica de pessoas com Down, naturais de Vitória da Conquista (Oliveira 2011, Oliveira e D’Ângelis 2012, Oliveira e Pacheco 2012, Oliveira e Pacheco 2013), porém tais características não afetam o sistema que permanece preservado, ou seja, oposições importantes no português são, de certa forma, garantidas na produção desses sujeitos. Diante disso, para verificar em que medida características fonatórias peculiares aos sujeitos com SD alteram ou não a qualidade das vogais produzidas por eles e se essas características trazem ou não implicações para o sistema vocálico, pautar-nos-emos na Teoria Fonte-Filtro, de Fant (1960), para análise do espaço vocálico de pessoas com Down em comparação ao de pessoas sem a síndrome.

A partir da análise do espaço vocálico, seremos capazes de avaliar quais as oposições fonológicas foram mantidas, quanto à tonicidade, nas diferentes posições silábicas (pretônica, tônica e átona final) e de que forma, em termos acústicos, essas oposições são garantidas. Para tanto, usaremos a proposta de caracterização das vogais do português feita por Matzenauer e Miranda (2009).

Assim, constituem objetivos desse trabalho a) determinar diferenças e semelhanças entre as vogais dos sujeitos com Down em relação àquelas produzidas por pessoas sem Down e, com isso, b) responder a questão central proposta - a diferença fonética, que percebemos na fala da pessoa com Down tem implicação para o sistema? Esse artigo está estruturado em mais 5 seções além dessas considerações iniciais: seção (2), em que apresentamos uma discussão sobre as características fonético-fonológicas das vogais orais do português; (3) em que apresentamos, em linhas gerais, as características da SD e alguns estudos sobre a produção vocálica por esses sujeitos; no item (4), apresentamos a metodologia adotada na pesquisa; em seguida, item (5), apresentamos e discutimos nossos resultados; por fim, em (6), apresentamos nossas considerações finais.

\section{Sistema vocálico do português do Brasil: contrastes fonológicos e características fonéticas}

O sistema vocálico do português do Brasil (PB) tem configuração diferenciada em função do tipo de tonicidade silábica. Um sistema composto por 7 vogais é encontrado na sílaba tônica, /a/, /e/, /é/, /i/, /ó/, /o/, /u/; havendo redução desse contraste nas demais posições: cinco vogais em posição pretônica (/a/, /e/, /i/, /o/, /u/), quatro vogais em posição postônica não final (/a/, /e/, /i/, /u/) e, finalmente, com três, em posição átona final (/a/, /i/, /u/). (Câmara Jr. 1992).

A oposição das vogais no português do Brasil atestada por Câmara Jr. (1992) pode ser explicada nos moldes da Fonologia Autossegmental, modelo idealizado por Goldsmith (1976). A proposta do autor é que a análise fonológica seja multilinear, o que significa que os traços podem ser colocados em níveis distintos em diversas camadas. 
É com base nos pressupostos da Fonologia Autossegmental que Clements (1985) e Clements e Hume (1995) desenvolvem a teoria da Geometria de Traços, segundo a qual as representações dos traços não envolvem matrizes bidimensionais como previsto por Jakobson (1967) e por Chomsky e Halle (1968), mas envolve, sim, uma geometria tridimensional que expressa a organização interna existente entre os traços fonológicos. Assim os traços fonológicos são dispostos em um diagrama arbóreo constituído de nós hierarquicamente ordenados. Os nós intermediários agregam classes de traços e os nós terminais são preenchidos pelos traços fonológicos.

Nessa perspectiva, as vogais, assim como qualquer outro som, podem ser descritas pela disposição de camadas de nós de traços organizados hierarquicamente e um dos nós que compõe o diagrama arbóreo das vogais é o nó de abertura composto pelos traços terminais tabertura 1 (ab1); tabertura 2 (ab2) e \pm abertura 3 (ab3). Na descrição das vogais do português, conforme proposta de Wetzels (1992), temos a configuração que apresentamos na figura 1:
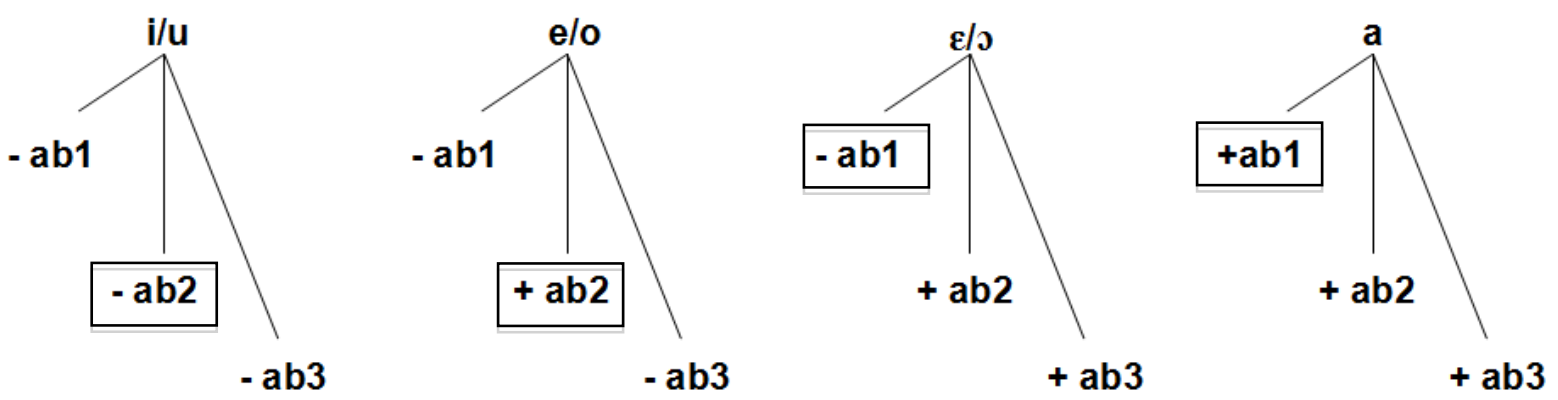

Figura 1: Representação esquemática dos traços de abertura para as vogais do PB com base em Wetzels (1992).

Como pode ser observado na figura 1, a oposição que existe entre as vogais altas e as médias altas se dá pelo traço [ab2]; entre as médias fechadas e as médias abertas, pelo traço [ab3] e, entre as médias abertas e a vogal aberta, pelo [ab1].

Nesse sentido, a redução do sistema vocálico em função do tipo de tonicidade silábica pode ser explicada pela perda do valor contrastivo dos traços que estão envolvidos na oposição dessas vogais. A neutralização que ocorre na sílaba pretônica se deve à perda do valor contrastivo do traço [ab3] das médias abertas e, na sílaba átona final, pela perda do valor contrastivo do traço [ab2] das médias fechadas.

Na busca pela compreensão do sistema vocálico do português do Brasil, um avanço para além dos traços de abertura pode ser encontrado em Matzenauer e Miranda (2009), cujo objetivo principal é a descrição da aquisição do sistema vocálico do PB. Com base em Clements e Hume (1995) e Fikkert (2005), as autoras propõem uma descrição do nosso sistema vocálico, a partir do seguinte conjunto de traços: [Labial, Coronal, Dorsal, \pm Alto, \pm Baixo, $\pm \mathrm{ATR}^{2}$ ].

A proposta é a de que traços monovalentes, de um único valor (Labial, Coronal e Dorsal), e binários, presença (+), ausência (-) ( \pm Alto, \pm Baixo, \pm ATR), combinam-se por meio da seguinte geometria (cf. figura 2), na descrição das nossas vogais:

\footnotetext{
${ }^{2}$ [ATR] - (advanced tongue root) - o que em português pode ser traduzido como "raiz da língua avançada".
} 


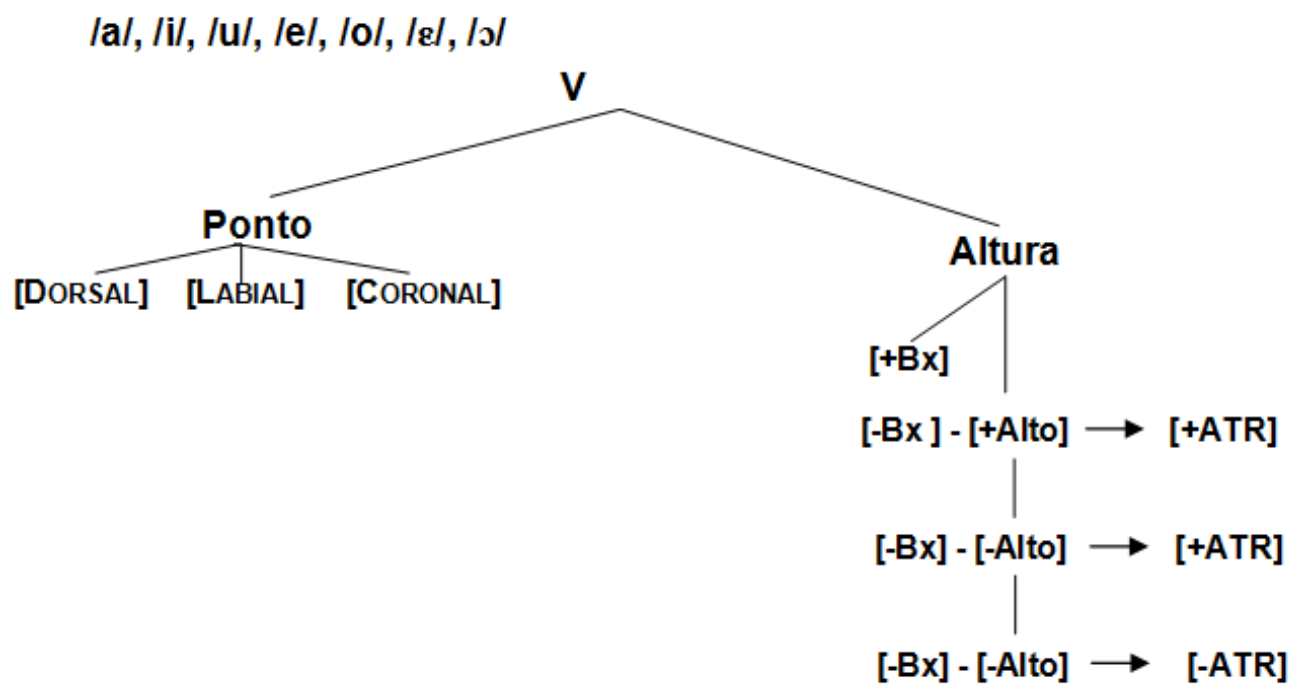

Figura 2: Geometria das vogais do PB, conforme traços de Clements e Hume (1995) e Fikkert (2005)

(Cf. Matzenauer e Miranda, 2009, p. 49)

A geometria vocálica, apresentada por Matzenauer e Miranda (2009), caracteriza-se pela presença do nó de Altura que substitui, na clássica proposta de Clements e Hume (1995), o nó de Abertura que domina os traços [ $\pm \mathrm{ab} 1]$, [ $\pm \mathrm{ab} 2]$ e [ $\pm \mathrm{ab} 3]$. Segundo as autoras, por meio dessa arquitetura, processos fonológicos que envolvem as vogais podem ser explicados, a partir de operações de desligamentos de certas camadas de traços, como ocorre, segundo elas:

\footnotetext{
i) na neutralização, por exemplo, da vogal pretônica, em que sucede um desligamento da camada relativa à altura, composta por [-bx, - alto, - ATR] t[E]rra -t[e]rreno, r[O]ta - r[o]teiro;

ii) na neutralização da vogal postônica final, em que há um desligamento da camada [-baixo, -alto, + ATR] e da camada [ baixo, -alto, - ATR] e manutenção da camada [-baixo, + alto, + ATR], leit[e],leit[i], livr[o], livr[u];

iii) na harmonia nominal, por meio do desligamento da camada 3 [- baixo, - alto, + ATR] m[e]nino, m[i]nino; e para o processo de abaixamento datílico e espondeu, pela ativação, segundo elas, da camada 4 , relativa à altura e pela co-ocorrência do traços [- baixo, -alto,- ATR] nos condicionamentos prosódicos, como p[E]tala, esquel[E]tico, rep[O]rter, d[O]cil. (Cf. Matzenauer e Miranda, 2009, p. 51-53).
}

A proposta de Matzenauer e Miranda (2009) tem a vantagem de contemplar a oposição, mesmo que secundária, que existe entre as vogais não arredondadas e arredondadas do português, ao trazer o traço [labial]. Além disso, a proposta traz o traço [ \pm ATR], que é importante para mostrar a oposição entre as médias abertas e médias fechadas.

A oposição vocálica em termos acústicos baseia-se, de acordo com Malmberg (1954), em grave /u/ vs agudo /i/, por um lado, e entre compacta /a/ vs difusa /i, u/, por outro. Como o português, todas as línguas alargam este sistema com uma série de vogais agudas: $\mathrm{i} \sim \mathrm{e} \sim$ é (Malmberg, 1954).

Dentro dos pressupostos da Teoria Fonte e Filtro da Produção da Fala, sistematizada por Fant (1960), essas características acústicas das vogais podem ser depreendidas a partir dos valores das frequências de ressonâncias, os formantes, que trazem pistas sobre as características articulatórias das vogais.

Assim, por meio do valor do primeiro formante, F1, pode-se inferir sobre a posição da língua no plano vertical que sofre influência do grau de abertura da boca e a frequência do segundo formante, F2, relaciona-se com a posição da língua no plano horizontal, ou grau de anterioridade (Kent e Read, 1992). 
Em linhas gerais, portanto, podemos afirmar que, na relação entre valores formânticos, configuração do trato vocal e tipos de vogais, o valor de F1 está relacionado com a elevação da língua na área vertical do trato vocal e com deslocamento da mandíbula de forma a estabelecer a diferença entre vogais altas e baixas; fechadas e abertas, conforme esclarece Kent e Read (1992).

Nesse sentido, podemos estabelecer as seguintes relações: a) quanto mais alta uma vogal, menor será o valor de $\mathrm{F} 1$; b) quanto mais baixa uma vogal, maior será o valor de $\mathrm{F} 1$; c) quanto mais aberta uma vogal, maior será o valor de $\mathrm{F} 1 \mathrm{e}$; d) quanto mais fechada uma vogal, menor o valor de F1.

Dessa forma, ainda de acordo com Kent e Read (1992), as vogais altas [i] e [u] apresentam os menores valores de $\mathrm{F} 1$, pois são vogais altas e fechadas, já a central [a] apresenta maiores valores em F1, por ser a vogal mais baixa e aberta. Segundo Maia (1985, p. 50) "o [i] soa mais agudo que o [a] porque tem dois formantes muito próximos numa região de frequência relativamente alta".

Se por um lado os valores de F1 de uma vogal apresentam estreita relação com a altura e abertura vocálicas, por outro, os valores de F2 apresentam estreita relação com a anterioridade e a posterioridade da zona de articulação (o que configura de forma distinta o tamanho do tubo ressoador), pois os valores do segundo formante estão relacionados com o deslocamento da língua na área horizontal do trato vocal.

Diante disso, podemos afirmar que, por meio dos valores de F2, somos capazes de estabelecer a diferença entre as vogais anteriores e as vogais posteriores ou recuadas, a partir da seguinte relação: a) quanto mais posterior uma vogal, menor será o valor de seu F2 e; b) quanto mais anterior uma vogal, maior será o valor de F2, o que pode ser verificado pelos valores de F2 das vogais altas [i] e [u], quais sejam, a vogal [i], que é a mais anterior, possui maior valor de F2 e a vogal [u], que é a mais recuada, possui o menor valor de F2.

Os valores das frequências formânticas per si constituem importantes parâmetros acústicos na identificação do tipo de vogal que se está produzindo. Além desse parâmetro, podemos também avaliar a qualidade vocálica por meio do cálculo da distância dos valores de F1 e F2, conforme Kent e Read (1992).

De um modo geral, vogais fechadas tendem a ter diferenças maiores entre os valores de F1 e $\mathrm{F} 2$, ao passo que as vogais abertas tendem a ter menor diferença entre esses valores.

Os valores de F1 e F2 são comumente usados na análise das vogais, pois esses valores constituem parâmetros acústicos eficazes na determinação da qualidade vocálica.

\section{A síndrome de Down: alterações orofaciais e produção vocálica}

A síndrome de Down é um evento genético que ocorre durante a divisão celular do embrião. Segundo Motta (1980, p. 147), em 1959, Lejeune demonstra uma ocorrência genética associada a um excesso de cromossomos no par 21.

Caracterizada como uma condição humana geneticamente determinada, em que há uma alteração no desenvolvimento das células do embrião (Mustacchi et al. 2000), a SD provoca atraso no desenvolvimento do corpo, bem como nas funções motoras e mentais das crianças. Como consequência, os sujeitos que têm a síndrome apresentarão um ritmo de desenvolvimento mais lento, isto é, atraso nas aquisições das habilidades físicas e mentais. 
Autores como Motta (1980), Otto et al (1998), Borges-Osório et al. (2001) são unânimes em afirmar que a hipotonia generalizada afeta toda a musculatura e os ligamentos dessas pessoas. Isso faz com que a criança com Down tenha um aspecto flácido, seja hipoativa, movimente-se menos e tenha reflexos e reações diminuídos.

Segundo Ideriha e Limongi (2007), crianças com diagnóstico de SD apresentam alterações do sistema estomatognático, que se caracterizam pela diminuição de tônus muscular em diferentes graus e pela alteração da dentição, pois a erupção dos dentes de leite é geralmente atrasada. Por outro lado, a mandíbula pequena leva, muitas vezes, à sobreposição e alteração no alinhamento dos dentes e isso prejudica as funções alimentares, em decorrência de problemas de maturação dos padrões de mastigação, sucção e deglutição.

A boca da pessoa com SD é pequena: algumas crianças mantêm a boca aberta e a língua projeta-se um pouco para fora, em função da macroglossia ou falsa macroglossia, decorrente da cavidade oral pequena, da hipotonia da musculatura orofacial e da fenda palato-ogival. Os sujeitos com essa alteração genética, mesmo na fase adulta, continuam a apresentar essa flacidez muscular, especialmente nos músculos da face. Além disso, à medida que a criança com síndrome de Down fica mais velha, a língua pode ficar com estrias. O céu da boca (palato) é mais estreito do que na criança sem síndrome, principalmente no caso de pessoas com Down que não foram amamentadas no peito.

Qualquer alteração labial, segundo Ideriha e Limongi (2007, p. 175), pode dificultar a participação dos lábios na sucção e interferir na competência labial e na formação da pressão intraoral. Isso resulta em escoamento do leite materno durante a amamentação e dificulta o desenvolvimento da fala, uma vez que os músculos envolvidos na sucção também estão associados aos movimentos da produção da fala.

Ideriha e Limongi (2007) salientam que a terapia miofuncional, no trabalho com a motricidade orofacial, atua nas desordens miofuncionais, restabelecendo ou adequando as funções de respiração, de sucção, de mastigação, de deglutição e de fala. Contudo, não sabemos os alcances dessas terapias, pois não há estudos que deem conta da relação entre terapias de motricidade orofacial e alteração da qualidade da fala desses sujeitos. Além disso, a criança com esta síndrome apresenta também problemas de acuidade e discriminação visual e auditiva e doenças respiratórias. Ademais, complicações como cardiopatias, problemas visuais, respiratórios, gastroesofágicos, que podem acometer os indivíduos com essa síndrome, acarretam um atraso ainda maior ao desenvolvimento psicomotor.

De modo geral, os autores até aqui referenciados argumentam que as alterações no trato vocal das pessoas com Down são generalizadas, o que nos leva a concluir que a dificuldade de articulação de alguns sons da língua se deve, entre outras coisas, à flacidez muscular e à macroglossia que em nossa opinião não só levam ao atraso na aquisição e no desenvolvimento da linguagem, se comparada com outras crianças, como também levam a uma fala adulta peculiar que pode comprometer inteligibilidade por parte de seus ouvintes.

Em ampla revisão sobre pesquisas que abordaram/abordam o tema desvio de fala e síndrome de Down realizadas desde a década de 1950, Kent e Vorperian (2013) concluem que são quatro as principais áreas de avaliação abrangidas pelos trabalhos encontrados: i) voz; ii) produção da fala; iii) fluência e prosódia e; iv) inteligibilidade.

O levantamento feito pelo autores sobre a voz cobre cerca de 600 sujeitos com Down pesquisados entre crianças e adultos. 
As pesquisas, realizadas entre 1949 a 1977, sobre as características vocais, têm se centrado na avaliação da frequência fundamental (f0), nível e qualidade de voz, sendo orientadas por hipóteses de que a SD está associada a uma disfonia característica. A pessoa com Down se caracterizaria por ter tom de voz baixo, voz rouca e áspera (Kent e Vorperian, 2013, p. 1). Estes estudos estimularam o interesse pelas características vocais de crianças com Down e levaram a trabalhos posteriores.

Com relação à fluência e prosódia, os estudos encontrados por Kent e Vorperian (2013) concluem sobre à ocorrência de tartamudez/gagueira que é um transtorno de comunicação que se caracteriza pela interrupção involuntária da fala e que atinge $1 \%$, em média, da população em geral, mas que atinge de 10 a $40 \%$ da população Down pesquisada. Esses trabalhos ainda apontam para perturbações prosódicas significativas.

Em se tratando da questão inteligibilidade, vários estudos levantados por Kent e Vorperian (2013) comprovam que a inteligibilidade é um problema sério na SD e persiste durante toda a vida para muitas pessoas, podendo ter efeitos negativos sobre atividades sociais e vocacionais. Muito poucos desses estudos têm relatado uma análise detalhada dos fatores subjacentes à reduzida inteligibilidade, supõe-se que os distúrbios de voz, articulação e ressonância, fluência e prosódia contribuam para o problema. Não se sabe apontar com exatidão, contudo, de que maneira tais dificuldades impactem para um déficit geral na inteligibilidade, nem se trocas articulatórias e desvios fonológicos aumentam o risco de prejuízo à inteligibilidade.

Em geral, nas pesquisas aventadas, é comum a associação entre os achados sobre a voz dos sujeitos pesquisados e as características do trato vocal deles, em especial, as alterações anatômicas e fisiológicas que apresentam.

Da revisão empreendida por Kent e Vorperian (2013) destacamos aquelas ligadas aos sons da fala. Passamos a seguir a fazer uma sumarização dos principais achados desses autores em relação a esse tópico.

No quesito "sons da fala", segundo Kent e Vorperian (2013), os estudos fonéticos e fonológicos mostram que o padrão de fala dos sujeitos com SD, ligado ao aparecimento tardio do balbucio, são uma combinação de atraso articulatório, anormalidade e desordenamento do desenvolvimento sonoro não observados na fala típica, consequências das alterações supraglóticas.

Os principais achados começam pelo atraso na ocorrência do balbucio canônico em bebês com Down e alterações nas características do balbucio dessa população. Em estudos sobre contrastes fonéticos na produção de vogal, Kent e Vorperian (2013) compilaram uma série de resultados que apontaram a existência de distorções nas produções vocálicas, como na delimitação de contraste entre vogal alta versus baixa, anterior versus posterior. Para os autores, tais distorções estariam associadas a uma limitação na regulação da altura e avanço da língua em função de fatores anatômicos e limitações motoras.

O surgimento e domínio de oposições consonantais em crianças com Down parecem ser mais tardios e seguem uma ordem normalmente estabelecida para as crianças em geral, havendo uma variabilidade interindivíduos bastante alta no desenvolvimento.

Sons consonantais do inglês, dominados em tenra idade como /d/, /t/, /n/ e /v/, /l/, /s/, /r/, não são comuns em pessoas de 15 a 22 anos de idade com Down. Alguns destes sons envolvem o ponto de articulação alveolar mais frequentemente articulado no inglês e que carrega alta carga de inteligibilidade nessa língua. 
Em resumo, além da alterações vocálicas e consonantais já expostas, os estudos arrolados por Kent e Vorperian (2013) ainda mencionaram outros características fonéticas que são afetados: simplificação dos clusters em posição final e inicial de palavra e dificuldade em manter contrastes que envolvem movimento e controle e paragem da língua. As conclusões gerais dos autores, a partir de pesquisas sobre percepção e articulação, são as de que existe um atraso global no desenvolvimento fonético/fonológico de pessoas com síndrome de Down. (Kent e Vorperian, 2013).

Embora ainda estejamos dando os primeiros passos nas pesquisas sobre a aquisição fonológica de sujeitos com Down, naturais de Vitória da Conquista, Bahia ${ }^{3}$, os estudos fonéticos que já empreendemos nos mostram uma clara relação entre as alterações do trato vocal e produção vocálica dessas pessoas.

Acreditamos que, no que se refere às vogais, as alterações orofaciais, percebidas em sujeitos com Down, atuam diretamente na alteração do desenvolvimento da fala e determinam diferenças no sinal acústico das vogais orais por eles produzidas.

Resultados de Oliveira (2011), Oliveira e D’Ângelis (2012) e Oliveira e Pacheco (2012) endossam nossa hipótese. Em trabalhos recentes sobre falantes do português brasileiro com SD, os pesquisadores além de descreverem o padrão acústico das vogais orais do PB produzidas por sujeitos com Down relacionam seus achados com as características anatômicas do trato vocal desses sujeitos e, dentre outras conclusões, os autores afirmam que as diferenças no padrão formântico desses segmentos estão relacionadas à hipotonia e à macroglossia apresentadas por pessoas com SD. A seguir, apresentamos algumas das principais conclusões a que chegam os autores sobre a produção das vogais orais por pessoas com Down, naturais de Vitória da Conquista/Ba.

Em relação à vogal aberta /a/, Oliveira (2011) e Oliveira e D’Ângelis (2012) afirmam que quando em posição tônica este segmento apresenta grande variabilidade em seu grau de abertura nas produções dos sujeitos com Down, ao contrário do que ocorre com os sujeitos sem Down. Relacionando configuração formântica e graus de tonicidade silábica, eles percebem que os sujeitos com Down tendem a produzir a vogal /a/ mais aberta quando está na primeira pretônica e não na posição tônica como é o esperado, quase não sendo feita a distinção entre vogais tônicas e átonas.

No tocante à vogal alta /i/, no que se refere à abertura, Oliveira e Pacheco (2012) afirmam que assim como em /a/, há também grande variabilidade no grau de abertura quando da sua produção pelos sujeitos com Down, sendo ela independente da tonicidade silábica em que se encontre; o sujeito com Down também não diferencia no aspecto formântico uma vogal tônica de uma átona.

Oliveira (2011) mostrou que na produção da vogal alta posterior /u/, há maior variabilidade, diferentemente da produção dos sujeitos sem Down. Segundo a autora, essa maior variabilidade ocorre, inclusive, em sílaba tônica; novamente, os sujeitos com Down não realizam a vogal /u/ com configuração formântica particular a depender da tonicidade silábica em que se encontre e isso ocorre tanto entre os homens quanto entre as mulheres; além disso, enquanto a configuração acústica de F2 nos sujeitos sem Down tende a ser menor o que lhe confere caráter mais posterior, nos sujeitos com Down a mesma vogal apresenta F2 maior, o que equivale a dizer que o deslocamento da língua destes em direção à cavidade laríngea é menor.

\footnotetext{
${ }^{3}$ Pesquisas sobre aquisição de fonologia em bebês com Down tem sido desenvolvido, desde 2012, no Núcleo Saber Down (CNPq-MEC) e Laboratório de Estudos em Fonética e Fonologia e tem evidenciado um atraso no aparecimento de balbucio e palavras. Além disso, pesquisas com adolescentes evidenciam uma tendência à simplificação de cluster e omissão e trocas de determinados sons na fala e também na escrita.
} 
Em relação às vogais médias, Oliveira (2011) mostra que há pouca variância na produção da vogal /é/ em sílaba tônica. Ressalta-se ser esta a única posição silábica em que essa vogal tem valor distintivo no português. Contudo, em relação à abertura, confirma-se a tendência da vogal baixa, pois essa vogal tende a apresentar o mesmo grau de abertura para todos os tipos de tonicidade silábica quando é produzida por sujeitos com Down. No que concerne à vogal média /ó/, os dados mostram alta variabilidade de realização nas posições pretônicas e baixa variabilidade na posição tônica, posição na qual temos de fato o seu valor fonológico. Em se tratando da relação entre configuração formântica e grau de tonicidade silábica fica evidente, pelos dados analisados, que os sujeitos com Down tendem a produzir essa vogal com menor grau de abertura nas sílabas pretônicas. A autora ratifica que a marca dialetal de manter a vogal média aberta em posição pretônica, característica de algumas cidades das regiões Norte-Nordeste do Brasil e bem presente no dialeto conquistense, como mostra o trabalho de Pacheco, Oliveira e Ribeiro (2013), é marcadamente mantida na fala desses sujeitos. (Cf. Oliveira, 2011)

Em se tratando das vogais médias altas /e/ e /o/, pode-se afirmar que a média alta anterior /e/ apresenta pouca variabilidade em sua produção, principalmente no que diz respeito ao F3. Também se verifica que a relação entre o padrão formântico e o grau de tonicidade silábico é estabelecida de forma diferente para as realizações da vogal /e/ falada pelos sujeitos com e sem Down, sendo que aqueles não apresentam alteração quanto ao grau de anterioridade em função da tonicidade silábica. As diferenças atestadas constituem evidências para a hipótese de que essas estariam mais relacionadas às características individuais do que a um padrão formântico que possa estar associado à síndrome.

Diante dos resultados acima resumidos, podemos confirmar a hipótese geral da tese da autora de que as alterações do trato vocal dos sujeitos com SD, quais sejam, a hipotonia orofacial e a macroglossia ou falsa macroglossia ou cavidade oral pequena acarretaria em alteração da qualidade das vogais produzidas por esses sujeitos. Contudo, a pergunta que fica é que implicações tais alterações fonéticas acarretam na marcação dos contrastes fonológicos do sistema vocálico do PB?

É impossível, pois, não levar em conta as diferenças entre o padrão acústico das vogais orais produzidas por sujeitos com Down em relação às mesmas vogais produzidas por pessoas sem a síndrome. Também é impossível não considerarmos que a razão disso é a alteração que aqueles sujeitos apresentam no seu trato vocal. Contudo, a nossa hipótese é a de que os sujeitos com Down, em meio as suas especificidades anatômicas, ajustam trajetórias articulatórias de modo a garantir os contrastes vocálicos de maior demanda. Seu padrão acústico diferenciado não compromete o que é opositivo.

\section{Materiais e métodos}

\subsection{Sujeitos da pesquisa}

Os dados foram coletados com 08 sujeitos no total, distribuídos entre: 04 sujeitos com Down, naturais e moradores de Vitória da Conquista/BA, com faixa etária entre 17 e 31 anos, dos sexos masculino e feminino, leitores, que frequentaram ou frequentam o ensino regular; 04 sujeitos sem Down, da mesma faixa etária, igualmente leitores, que frequentam ou frequentaram o ensino regular. Cumpre salientar que, para uma comparação mais precisa dos dados, os sujeitos sem Down participantes dessa pesquisa possuem baixa estatura, como os sujeitos com Down, além de possuírem pesos próximos aos dos sujeitos com SD. Dessa forma, fomos capazes de garantir que os dois grupos de sujeitos analisados possuíam tubos relativamente semelhantes entre si. 
Essa pesquisa tem autorização do Comitê de Ética em Pesquisa e foram assinados os Termos de Consentimento Livre e Esclarecidos (TCLE), (CAAE 04853012.6.0000.0055), por todos os sujeitos e/ou responsáveis pelos sujeitos pesquisados.

\subsection{Corpus e gravação dos dados}

Os dados foram obtidos a partir da repetição de sintagmas nominais, formados a partir de palavras núcleos que continham as vogais do $\mathrm{PB}$ esperadas para as diferentes posições silábicas pretônica $(\mathrm{PT})$, tônica $(\mathrm{T})$ e átona final $(\mathrm{AF})$. Para garantir número amostral mínimo para análise estatística, foi criado um corpus composto de cinco palavras para cada vogal nas diferentes posições silábicas. A escolha das palavras se deu mediante busca em dicionário Aurélio impresso e eletrônico. Cada sintagma, tais como 'Abacate pequeno' foi inserido em slides que foram projetados para leitura.

A gravação dos dados ocorreu no Laboratório de Pesquisa e Estudos em Fonética e Fonologia (LAPEFF-UESB), que é equipado com uma câmara acústica, projetores de slides, computadores de última geração, placa de som e microfone de alta qualidade, e software de gravação de dados de fala. Na captação sonora, foi utilizada placa M-box 2, da M-Áudio, conectada a um notebook, microfone da AKJ, acoplado à placa. Foi estabelecida taxa de amostragem de $44 \mathrm{kHz}$. A M-box 2 exige a utilização de programa de captação sonora específico, o Pro tools LE.

\subsection{Obtenção das frequências de F1 e F2 e geração dos gráficos de dispersão para análise do espaço vocálico}

As frequências dos três primeiros formantes foram obtidas no estado estacionário de cada uma das vogais nas diferentes posições silábicas. As mensurações foram obtidas por meio do software Praat, (Boersma e Weenink, 2006), a partir da adaptação de script desenvolvido por Ferreira (2008).

Foram realizadas as extrações das frequências formânticas das vogais aqui estudadas, em sílabas PT, T e AF, o que resultou num total 11760 dados referentes a: i) 98 palavras (15 [a], 13 [e], 13 [é], 16 [i], 13 [o], 13 [ó], 15 [u]); ii) 05 repetições; iii) 03 formantes (F1, F2, F3); iv) 08 sujeitos [4 com síndrome (02 homens e duas mulheres) e 4 sem síndrome ( 02 homens e 02 mulheres)].

Ressaltamos que, neste artigo, são utilizadas apenas as frequências de F1 e de F2, para delimitação do espaço vocálico.

Após extração das frequências formânticas, foram calculados os valores médios dessas frequências a partir dos quais foram gerados os gráficos de dispersão, por meio de script executado no Praat. Os gráficos de dispersão vocálica consistem na plotagem de F1 e F2 em um plano cartesiano em que as frequências de F1 ficam na ordenada e de F2 na abscissa.

\section{Resultados e discussão}

A realidade das vogais orais do português é muito complexa e vai para além das cinco letras latinas usadas na escrita, como ressalta Câmara Jr. (1992, p. 39). A tonicidade da sílaba na palavra é um fator importante para determinar as possibilidades vocálicas para aquela posição, o que nos leva, ao estudar o nosso sistema vocálico, a considerar se estamos diante de uma sílaba pretônica, tônica ou postônica. 
Diante disso, passemos a analisar os resultados obtidos, considerando as vogais em sílaba pretônica, sílaba tônica e átona final produzidas por sujeitos com síndrome de Down e sem a síndrome.

\subsection{Espaço vocálico em sílaba pretônica}

Avaliando os dados da posição PT, conforme gráficos 1 e 2, observamos que, em ambos os grupos de sujeitos, há sobreposição de certas regiões espectrais. Focando nosso olhar para os dados do gráfico 1, verificamos acentuada sobreposição das regiões espectrais das vogais médias abertas e médias fechadas, bem como acentuada sobreposição entre as vogais arredondadas [o, ó, u].

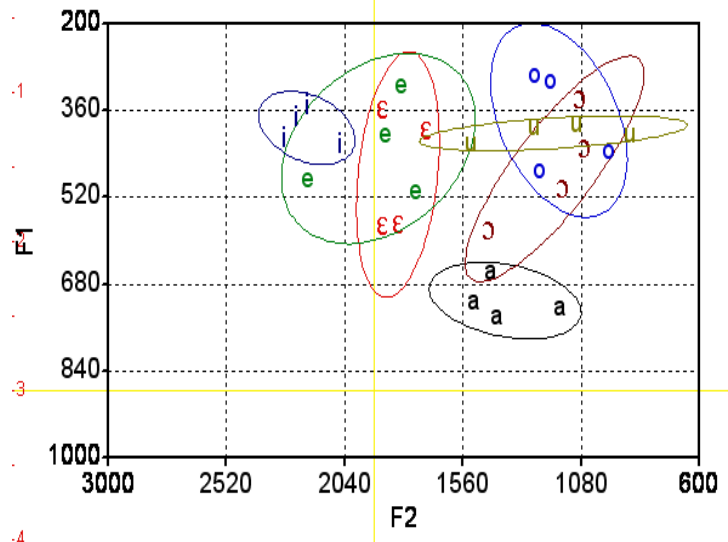

Gráfico 1: Dispersão de F1 e F2 médios, em Hz, das vogais orais em posição pretônica (com Down).

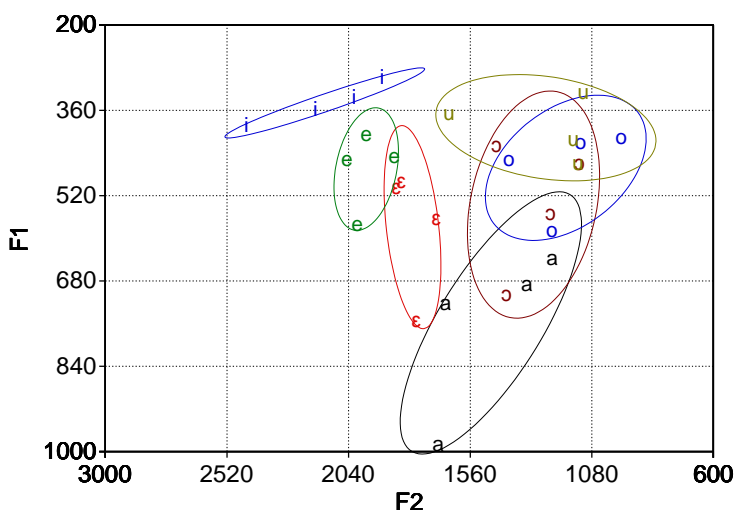

Gráfico 2: Dispersão de F1 e F2 médios, em Hz, das vogais Orais em Posição Pretônica (sem Down).

Os dados do gráfico 2 nos mostram que sujeitos sem a síndrome apresentam sobreposição entre as médias abertas e médias fechadas menos acentuada do que a observada para os sujeitos com SD. Mas por outro lado, sujeitos sem a síndrome possuem uma leve sobreposição entre as regiões espectrais da vogal /a/ com as regiões espectrais das vogais médias arredondadas. Os dois grupos de sujeitos apresentam sobreposição considerada entre as regiões espectrais das vogais arredondadas.

Os dados dos gráficos 1 e 2, caracterizados por sobreposições de certas zonas espectrais, refletem perfeitamente a variabilidade dessas vogais na sílaba pretônica, no que se refere às vogais médias, que são suscetíveis a sofrer vários processos fonológicos, a saber: neutralização, alteamento, harmonia vocálica e metafonia, como posto por Matzenauer e Miranda (2009).

Apesar das sobreposições de algumas zonas espectrais, é possível observar tanto para os sujeitos SD quanto para os sujeitos sem SD que não há sobreposição entre as vogais altas anterior e posterior, respectivamente /i/ e /u/, bem como não há sobreposição entre essas vogais e a vogal /a/.

Esses dados acenam para a hipótese de que, na posição pretônica, em meio à variabilidade vocálica típica desse tipo silábico, há certos contrastes que devem ser preservados. De um lado o contraste de ponto, [coronal] x [dorsal], e de outro o contraste de altura, [+Bx] x [-Bx, +Alto, + ATR]. Os resultados encontrados na análise da posição pretônica, para sujeitos com Down sumarizados no quadro 1, a seguir: 


\begin{tabular}{|c|c|c|}
\hline $\begin{array}{l}\text { Contraste de } \\
\text { ponto }\end{array}$ & $\begin{array}{c}\text { [Coronal] } \\
\text { /i,e/ }\end{array}$ & $\begin{array}{c}\text { [Dorsal] } \\
\text { la,u,o/ }\end{array}$ \\
\hline $\begin{array}{l}\text { Contraste de } \\
\text { altura }\end{array}$ & 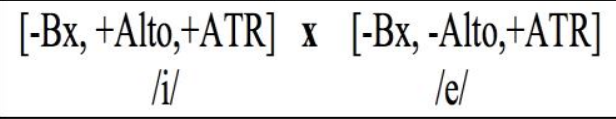 & $\begin{array}{c}{[+\mathrm{Bx}] \mathbf{x}[-\mathrm{Bx},+\mathrm{Alt} 0,+\mathrm{ATR}] \mathbf{x}[-\mathrm{Bx},-\mathrm{Alt} 0,+\mathrm{ATR}]} \\
/ \mathrm{a} / \mathrm{/u} / \mathrm{l} / \mathrm{l} /\end{array}$ \\
\hline $\begin{array}{c}\text { Avaliação das } \\
\text { zonas espectrais }\end{array}$ & \multicolumn{2}{|c|}{$\begin{array}{l}\text { a) Ausência de sobreposição entre vogal anterior e vogal posterior } \\
\text { b) Ausência de sobreposição entre vogal baixa e vogais altas } \\
\text { c) Alta sobreposição entre as regiões espectrais das vogais médias abertas e médias fechadas e entre } \\
\text { arredondadas. }\end{array}$} \\
\hline
\end{tabular}

Quadro 1: Síntese dos contrastes de ponto e altura preservados e situação das zonas espectrais na produção de vogais pretônicas por sujeitos com e sem Down.

A configuração dos contrastes preservados propostos a partir das zonas espectrais (cf. Quadro 1), além de dar conta da oposição existente entre /a/, /e/, /o/ /i/ e /u/, observada na posição pretônica, explica também o processo de neutralização que ocorre entre as vogais médias abertas e as vogais médias fechada, que para Matznauer e Miranda (2009) seria decorrente do desligamento da camada relativa à altura composta por [-bx, -alto, -ATR]. A falta de oposição entre [-bx, -alto, +ATR] e [bx, -alto, -ATR] pode ser visualizada pela alta sobreposição das zonas espectrais referentes a essas duas vogais.

A delimitação pouco expressiva entre as zonas espectrais das vogais altas e médias altas, se comparada com as vogais altas e baixas pode explicar os casos de harmonia nominal como por exemplo (m[i]nino), que, segundo Matznauer e Miranda (2009) é decorrente do desligamento da camada 3 [- baixo, - alto, + ATR].

\subsection{Espaço vocálico em sílaba tônica}

Na comparação da produção vocálica de sujeito com e sem a síndrome de Down a que nos propomos fazer, um novo cenário se descortina para a realidade das vogais em sílaba tônica, como se atesta nos gráficos 3 e 4.

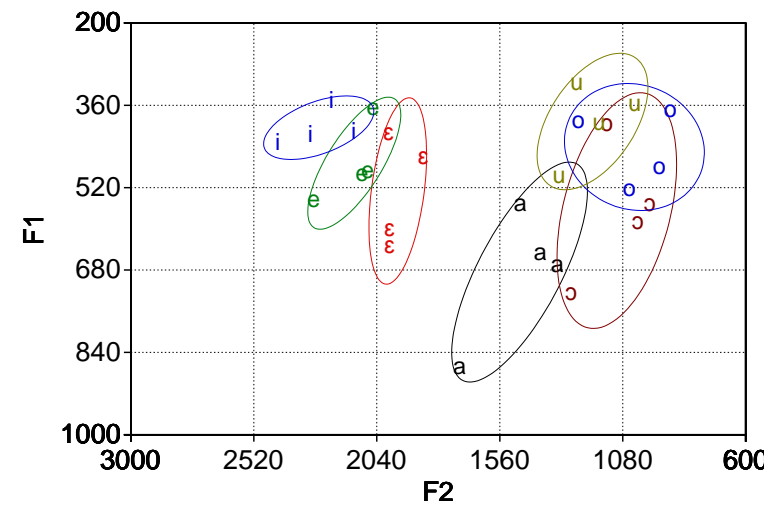

Gráfico 3: Dispersão de F1 e F2 médios, em Hz, das vogais orais em posição tônica (com Down)

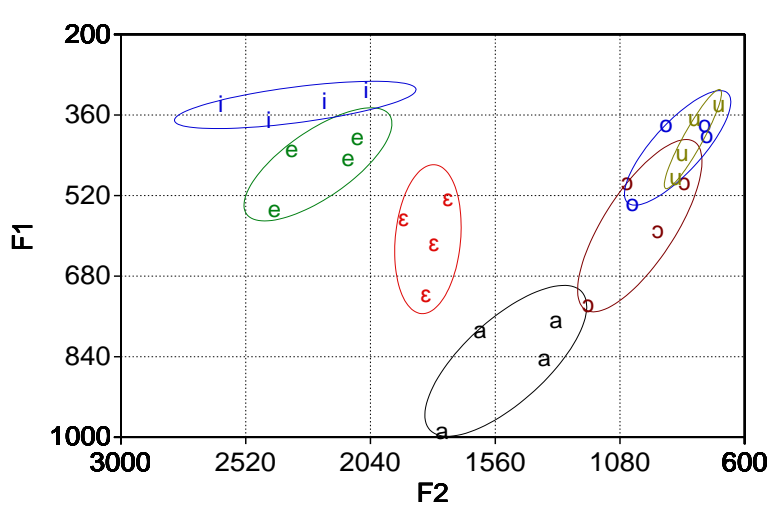

Gráfico 4: Dispersão de F1 e F2 médios, em Hz, das vogais orais em Posição tônica (sem Down)

Se por um lado o gráfico de dispersão das vogais produzidas por sujeitos sem a síndrome apresenta 5 regiões espectrais bem definidas (cf. gráfico 4), por outro, o dos sujeitos com a síndrome apresenta somente duas. O gráfico de dispersão dos SD (cf. gráfico 3) se caracteriza por possuir os valores de F1 e F2 das vogais [i, e, é] concentrados à esquerda do gráfico e, concentrados à direita, os valores das frequências formânticas de $[u, o, o ́, a]$. 
Diante dessa configuração, o que observamos de fato nesse gráfico é, respectivamente, o agrupamento das vogais [coronal] de um lado e do outro o das vogais [dorsal]. A princípio a oposição preservada na fala desses sujeitos é então a de ponto [coronal] x [dorsal].

Ainda de acordo com o gráfico 3, apesar da leve sobreposição das zonas espectrais das vogais [u, o, ó, a], os valores de F1 permitem observar dentre as vogais [dorsal] dois subgrupos que opõem essas vogais em $[+\mathrm{Bx}]$, que contemplam a vogal [a] versus $[-\mathrm{Bx}]$, que contemplam as vogais /u, o, ó/.

Dessa forma, podemos afirmar que na sílaba pretônica, o gráfico de dispersão das vogais, produzidas por sujeitos com SD, evidencia preservação dos contrastes [coronal] x [dorsal], de um lado e, de outro, o contraste [+Bx] x [-Bx], entre as vogais [dorsal]. Nesse mesmo contexto, não é mantido o contraste [+Alto], qual seja a vogal /u/ versus [-Alto], as vogais /o, ó/, entre as vogais [labial]; bem como também não é mantido o contraste entre [+ATR], /e, o/ versus [-ATR], /é, ó/, entre as vogais [-Bx, -Alto].

Ao analisarmos o gráfico de dispersão dos sujeitos sem SD, percebemos obviamente uma configuração que se assemelha a dos sujeitos com SD, mas que também apresenta diferenças em relação a essa.

No que se refere à semelhança entre a produção vocálica dos sujeitos com e sem SD, verificamos sobreposição das zonas espectrais das vogais arredondadas /u, o, ó/ presente nos dois gráficos de dispersão (cf. gráficos 3 e 4). Salta-nos aos olhos o fato de esses dois grupos de sujeitos não delimitarem acusticamente as zonas das vogais arredondadas, o que nos leva a supor que nos dois casos o contraste [+Alto] e [-Alto] entre as vogais [labial] não pode ser encontrado no gráfico de dispersão.

Além disso, é importante ressaltar que em ambos os grupos, observamos que o padrão formântico da vogal /a/ encontra-se mais à direita do gráfico, posição majoritariamente ocupada pelas vogais [dorsal], /u, o, ó/. Nesse sentido, a oposição verificada entre [coronal] x [dorsal] pode ser visualizada, bem como pode ser visualizada entre as vogais [dorsal], a oposição [+Bx ] e [-Bx], que, respectivamente, coloca a vogal /a/ em oposição as vogais /u, o, ó/ (cf. gráfico 4). Em síntese podemos afirmar que os contrastes mantidos na tônica são os mesmos mantidos na pretônica: [coronal] x [dorsal] e [+bx] e [-bx], como demonstrado no quadro $2 \mathrm{a}$.

\begin{tabular}{|c|c|c|}
\hline $\begin{array}{l}\text { Contraste de } \\
\text { ponto }\end{array}$ & $\begin{array}{l}\text { [Coronal] } \\
\text { li,el }\end{array}$ & $\begin{array}{l}{[\text { Dorsal] }} \\
|a, u, 0|\end{array}$ \\
\hline $\begin{array}{l}\text { Contraste de } \\
\text { altura }\end{array}$ & 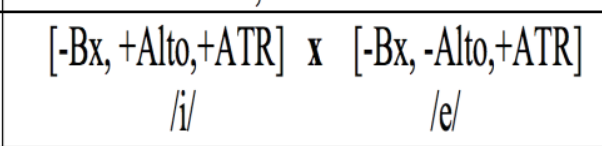 & 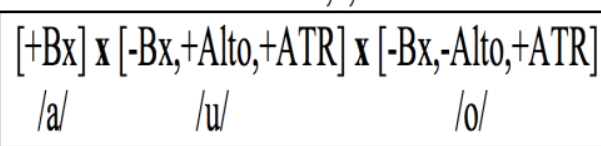 \\
\hline $\begin{array}{l}\text { Avaliação das } \\
\text { zonas espectrais }\end{array}$ & \multicolumn{2}{|c|}{$\begin{array}{l}\text { a) Duas zonas espectrais bem definidas: i) vogais anteriores ii) vogais posteriores e vogal central } \\
\text { b) Sobreposição de zonas espectrais entre as arredondadas. }\end{array}$} \\
\hline
\end{tabular}

Quadro 2a: Síntese dos contrastes de ponto e altura preservados e avaliação das zonas espectrais na produção de vogais tônicas por sujeitos com Down.

Mas, diferentemente do que foi constatado no gráfico de dispersão das vogais produzidas por sujeitos com SD (cf. gráfico 3), o gráfico de dispersão das vogais produzidas por sujeitos sem SD (cf. gráfico 4) se caracteriza por apresentar três zonas espectrais bem delimitadas entre as vogais [coronal]. 
Os sujeitos sem a $\mathrm{SD}$, para sílaba tônica, marcam acusticamente a produção das vogais /i, e, é/. Nesse sentido, verificamos entre as vogais [coronal] o contraste de [coronal, -Bx, +Alto] versus [coronal, -Bx, -Alto], ou seja, /i/ versus /e, é/ e dentre as vogais [coronal, -Bx, -Alto] o contraste [coronal, -Bx, -Alto, +ATR] versus [ coronal, -Bx, -Alto, -ATR], isto é, le/ versus lé/, como apresentando no quadro $2 b$.

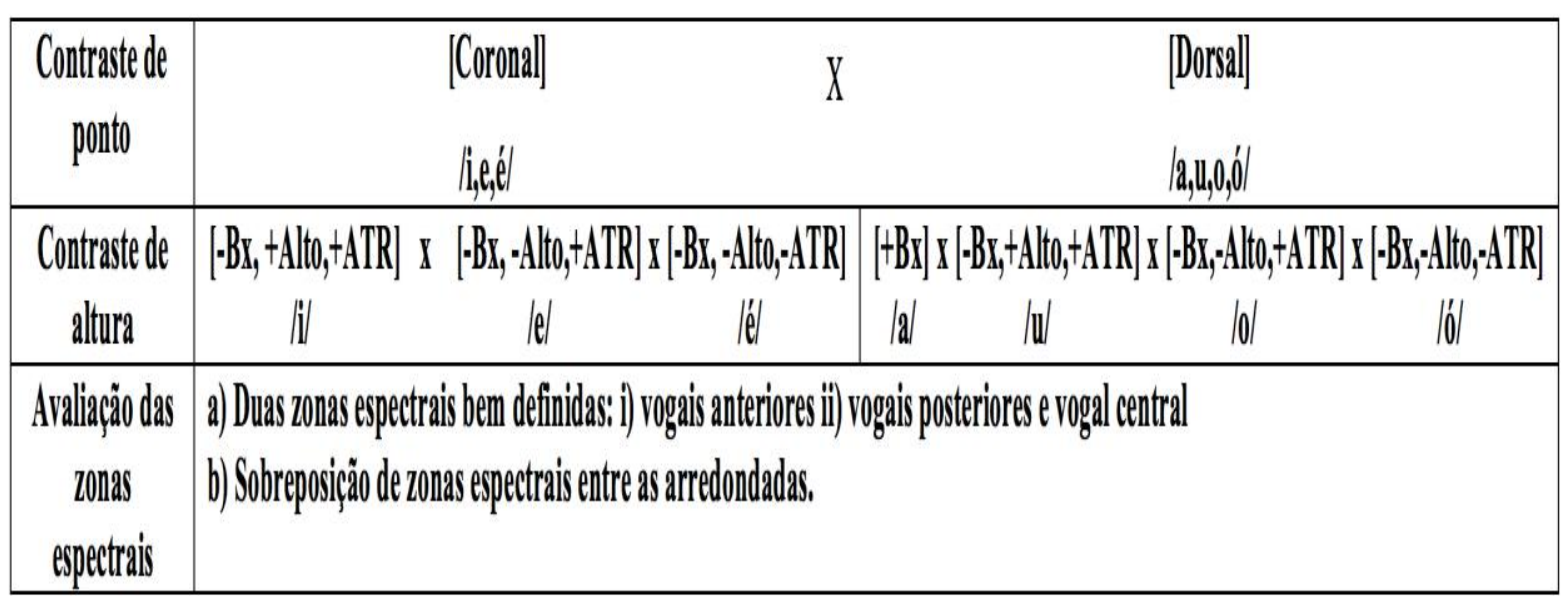

Quadro 2b: Síntese dos contrastes de ponto e altura preservados e avaliação das zonas espectrais na produção de vogais tônicas por sujeitos sem Down.

\subsection{Espaço vocálico em sílaba átona final}

Caminhando mais um pouco, chegamos enfim à análise das vogais em sílaba $\mathrm{AF}$, gráficos $5 \mathrm{e}$ 6, em cada um dos quais verificamos uma configuração triangular bem definida na produção vocálica desses grupos de sujeitos.

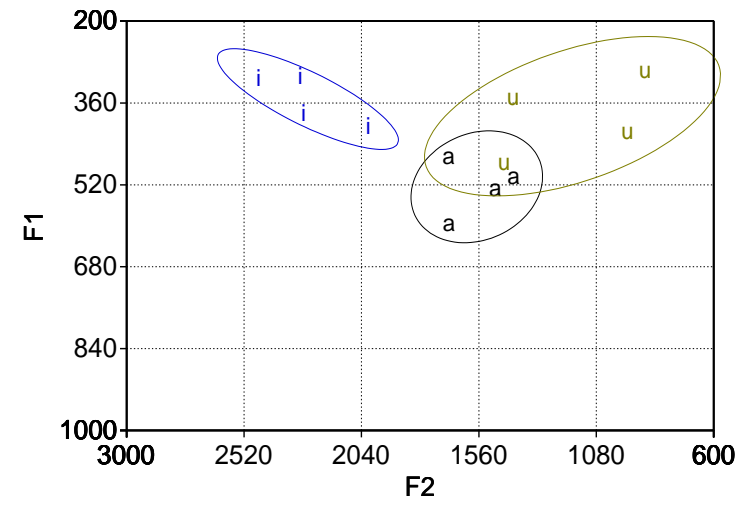

Gráfico 5: Dispersão de F1 e F2 médios, em Hz, das vogais orais em posição átona final (com Down).

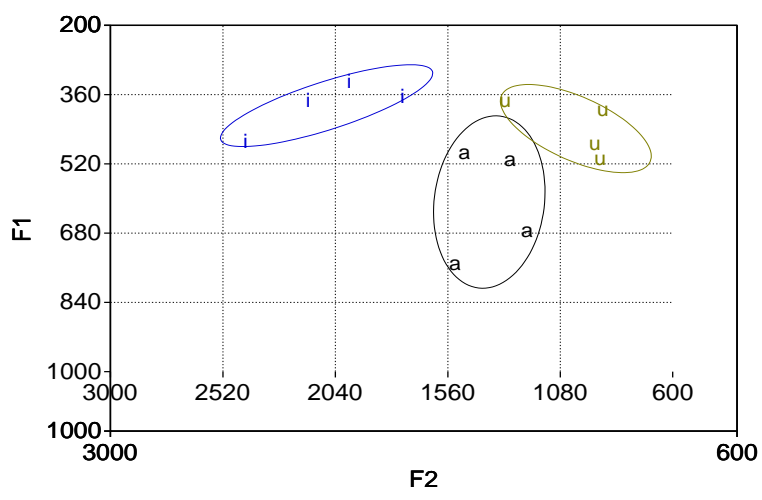

Gráfico 6: Dispersão de F1 e F2 médios, em Hz, das vogais orais em posição átona final (sem Down).

Embora tenhamos configuração triangular bem definida, a tendência de sobreposição entre as zonas espectrais das vogais [dorsal] /a/ e /u/ observada nas sílabas PT e T é igualmente observada para as vogais em AF produzidas por sujeitos com SD (gráfico 5). Mas apesar disso, conseguimos identificar as zonas de concentração das frequências de cada uma dessas vogais.

Como observado nos outros tipos silábicos vistos até aqui, na sílaba AF mantem-se o contraste entre [coronal], /i/, versus [dorsal], /a, u/, e entre as vogais [dorsal] a oposição entre [dorsal, +Bx], /a/ versus [dorsal, -Bx, +Alto,+ATR], /u/. 
Exceção feita à sobreposição entre as zonas de /a/ e /u/ observada na produção dos sujeitos com SD, configuração similar da dispersão vocálica é observada na produção das vogais em sílaba AF produzidas por sujeitos sem SD (gráfico 6). Assim, à semelhança do que se observa nos sujeitos sem SD, a oposição encontrada nas vogais em sílaba AF é entre [coronal], /i/, versus [dorsal], /a, u/, e entre as vogais [dorsal] a oposição entre [dorsal, +Bx], /a/ versus [dorsal, -Bx, +Alto,+ATR], /u/. Em síntese:

\begin{tabular}{|c|c|c|}
\hline Contraste de ponto & $\begin{array}{ll}\text { CCoronal] } & \mathrm{X} \\
/ \mathrm{i} / & \end{array}$ & $\begin{array}{c}\text { [Dorsal] } \\
/ \mathrm{a}, \mathrm{u}, /\end{array}$ \\
\hline Contraste de altura & $\begin{array}{c}{[-\mathrm{Bx},+ \text { Alto, }+ \text { ATR }]} \\
/ \mathrm{i} /\end{array}$ & $\begin{array}{c}{[+\mathrm{Bx}] \mathbf{x}[-\mathrm{Bx},+\mathrm{Alto},+\mathrm{ATR}]} \\
/ \mathrm{a} /\end{array}$ \\
\hline $\begin{array}{c}\text { Avaliação das zonas } \\
\text { espectrais }\end{array}$ & \multicolumn{2}{|c|}{$\begin{array}{l}\text { a) Tendência à sobreposição entre as dorsais [a] vs [u] } \\
\text { b) Ausência de sobreposição entre vogal anterior e vogal } \\
\text { posterior. }\end{array}$} \\
\hline
\end{tabular}

Quadro 3: Síntese dos contrastes de ponto e altura preservados e avaliação das zonas espectrais na produção de vogais átonas finais por sujeitos com e sem Down.

\subsection{Discussão dos dados}

Apesar dos padrões acústico distintos observados para os dois grupos de sujeitos, como mostram os trabalhos de Oliveira (2011), Oliveira e D’Ângelis (2012), Oliveira e Pacheco (2012) e Oliveira e Pacheco (2013), as análises de dispersões vocálicas aqui realizadas evidenciam que constastes fonológicos importantes são garantidos nas produções vocálicas dos sujeitos com SD, a saber, o contraste entre [coronal] versus [dorsal] e o contraste $[+\mathrm{Bx}]$ versus $[-\mathrm{Bx},+\mathrm{Alto},+\mathrm{ATR}] \mathrm{o}$ que garante o contraste de ponto e abertura, oposições cruciais na organização do sistema fonológico do português.

Mas por outro lado, o contraste entre [-Bx,+Alto, +ATR] versus [-Bx,-Alto, +ATR] e o contraste entre $[-\mathrm{Bx},-$ Alto, $+\mathrm{ATR}]$ versus $[-\mathrm{Bx},-\mathrm{Alto},-\mathrm{ATR}]$ na sílaba tônica, requeridos pelo nosso sistema na sílaba tônica não é preservado na produção dos sujeitos com SD.

Diante desses resultados, perguntamos: de que maneira a hipotonia orofacial e/ou a macroglossia pode $(m)$ justificar/explicar certas realizações das vogais orais produzidas por sujeitos com Down que comprometem certas oposições fonológicas?

Sabemos que a realidade física de um segmento está diretamente relacionada com as configurações assumidas pelo trato vocal durante a sua emissão, como fica evidente na proposta de Teoria Fonte-Filtro (Fant, 1960). Assim, a hipotonia orofacial pode explicar a realização menos fechada da vogal /i/ e menos aberta da vogal /a/ pelos sujeitos com síndrome, como descrevem Oliveira e D’Ângelis (2012), Oliveira e Pacheco (2012) e Oliveira e Pacheco (2013).

As autoras afirmam que os maiores valores de $\mathrm{F} 1$ atestados para a vogal /i/ decorrem do fato de os indivíduos com SD não contarem com um controle muscular necessário para se obter o mínimo possível de abertura, exigido na produção dessa vogal fechada. Assim, essas alterações pontuais da interferência das características da anatomia orofacial dos sujeitos com Down nos padrões acústico-articulatórios das vogais por eles produzidas podem ser também sentidas de um modo geral em todo o quadro vocálico, o que obviamente tem consequência para as marcações de certo contrastes fonológicos, especificamente para aqueles que opõem segmentos cujas trajetórias articulatórias são muito próximas. 
Nesse sentido, sugerimos aqui que a ausência do contraste $[-\mathrm{Bx},+$ Alto, +ATR $]$ versus $[-\mathrm{Bx},-$ Alto, + ATR] observada tanto na série das vogais [coronal] quanto na série das vogais [dorsal] possa ser explicada/justificada pela macroglossia, isso porque as camadas de traços [-Bx,+Alto, +ATR] e [-Bx,-Alto, +ATR] dão conta de expressar contrastes entre segmentos produzidos em regiões muito próximas do trato vocal: /i/ x /e/; /u/ x /o/.

Acreditamos que essa característica anatômica compromete a realização de segmentos como [i, e, é], todos produzidos na região anterior do trato vocal, bem como os segmentos [u, o, ó] todos produzidos na cavidade posterior. O limite articulatório envolvido na produção dessas vogais é muito pequeno, o que traz dificuldade para esses sujeitos. Em consequência disso o contraste [$\mathrm{Bx},+$ Alto, +ATR] versus $[-\mathrm{Bx},-\mathrm{Alto},+\mathrm{ATR}]$ não é tão evidente nas produções dos sujeitos com SD como mostram os gráficos de dispersão aqui analisados.

O outro contraste fonológico pouco evidenciado no gráfico de dispersão do sujeitos com SD foi o contraste [-Bx,-Alto, +ATR] versus [-Bx,-Alto, -ATR] que expressa a oposição entre /e/ x /é/ e entre $/ \mathrm{o} / \mathrm{x} / \mathrm{o} / . \mathrm{O}$ traço [ATR] (advanced tongue root) envolvido nessas camadas diz respeito ao avanço da raiz da língua na produção do som. Segundo Corbera Mori (2001, p. 166), "na emissão de sons [ATR] a raiz da língua é puxada em direção à parte anterior do trato vocal, o que faz com que a cavidade faríngea se amplie e produza uma elevação do corpo da língua”.

Considerando as palavras de Corbera Mori (2001), podemos afirmar que a implementação da oposição entre [-Bx,-Alto, +ATR] versus [-Bx,-Alto, -ATR] requer um esforço muscular diferenciado para marcar um e outro segmento, o que, dada a hipotonia muscular característica de sujeitos com SD, pode ser um empecilho para marcar esse contraste vocálico. Novamente, é difícil para o sujeito com SD marcar fonologicamente segmentos foneticamente muito semelhantes.

As discussões aqui desenvolvidas nos acenam para a hipótese de que as características anatômicas de sujeitos com SD comprometem contrastes fonológicos que expressam pequenas diferenças articulatórias segmentais. Oposições que expressam diferenças extremas são garantidas na fala desse sujeito. Nesse sentido, podemos afirmar que contrastes que envolvem trajetórias articulatórias mais finas podem não ser tão evidentes na fala desses sujeitos, mas contrastes fonológicos responsáveis pela delimitação de sentido - vogais abertas versus vogais fechadas traço de abertura, vogais anteriores versus vogais posteriores - traço de ponto - estão presentes na produção dos sujeitos com Down pesquisados.

\section{Considerações Finais}

É impossível não notarmos as diferenças entre o padrão acústico das vogais orais produzidas por sujeitos com Down em relação às mesmas vogais produzidas por pessoas sem a síndrome. Também é impossível não considerarmos que a razão disso é a alteração que aqueles sujeitos apresentam no seu trato vocal. Contudo, seu padrão acústico diferenciado não compromete todos os contrastes fonológicos do português.

Em outras palavras, tanto para sujeito com, bem como para sujeito sem Down, somos capazes de identificar zonas espectrais que opõem vogais fechadas de vogais abertas; vogais anteriores de vogais posteriores, por exemplo. Além disso, se por um lado as especificidades anatômicas dos sujeitos com Down podem, de fato, alterar-lhe os padrões formânticos de suas vogais, podendo trazer para o seu ouvinte uma dificuldade de compreensão a uma primeira vista, não há comprometimento do ato comunicativo, pois, em suas realizações sonoras, macro características acústico-articulatórias das vogais estão garantidas. 
O sistema fonológico do $\mathrm{PB}$, no que se refere às vogais orais, portanto, está preservado, nos sujeitos com síndrome de Down, naturais de Vitória da Conquista.

As discussões aqui desenvolvidas nos permitem concluir que as características anatômicas de sujeitos com SD comprometem contrastes fonológicos que expressam pequenas diferenças articulatórias segmentais, mas as oposições que expressam diferenças extremas, são mantidas na fala dos sujeitos com SD.

Podemos então afirmar que contrastes que envolvem trajetórias articulatórias mais finas tais como implementação da oposição entre [-Bx,-Alto, +ATR] versus [-Bx,-Alto, -ATR] requerem um esforço muscular diferenciado para marcar um e outro segmento, o que, dada a hipotonia muscular característica de sujeitos com SD, pode ser um empecilho para marcar esse contraste vocálico, sendo difícil para o sujeito com SD marcar fonologicamente segmentos foneticamente muito semelhantes. Por outro lado, o contraste entre [coronal] versus [dorsal] e o contraste [+Bx] versus [$\mathrm{Bx},+$ Alto, +ATR], que garantem o contraste de ponto e abertura, oposições cruciais na organização do sistema fonológico do português, se mantem evidentes na fala desses mesmos sujeitos.

Diante do exposto podemos afirmar que em meio as suas especificidades anatômicas, os sujeitos com Down ajustam trajetórias articulatórias de modo a garantir os contrastes vocálicos de maior demanda, como todo e qualquer falante.

\section{Referências bibliográficas}

Boersma, Paul e David Weenink. 2006. PRAAT: doing phonetics by computer (Version 4.4.23) (Computer program), retrieved 12 June, Disponível em http://www.praat.org.

Borges-Osório, Maria Regina e Waynce M. Robinson. 2001. Genética humana, 2a . ed. Porto Alegre, Artmed.

Câmara Jr, Joaquim Mattoso. 1992. Estrutura da língua portuguesa. 21 a ed. Petrópolis, Vozes.

Clements, George N. 1895. The geometry of phonological features. Phonology Yearbook, 2: 225252.

Clements, George N. e Elizabeth V. Hume. 1995. The internal organization of speech sounds. Em John Goldsmith (ed.), The handbook of phonological theory, Cambridge, MA/ Oxford: Basil Blackwell: 245-306.

Chomsky, Noam e Morris Halle. 1968. The sound pattern of English. New York, Evanston/London, Harper \& Row.

Corbera Mori, Angel H. 2012. Fonologia. Em Fernanda Mussalim e Anna Christina Bentes (eds.) Introdução à Linguística. V. 1. 9a. ed., São Paulo, Cortez Editora:157-191

Fant, Gunnar. 1960. Acoustic theory of speech production, Mouton, The Hague.

Ferreira, Letânia. 2008. High initial tones and plateaux in spanish and portuguese neutral declaratives: consequences to the relevance of $F 0$, duration and vowel quality as stress correlates. Tese de Doutorado, University of Illinois Urbana-Champaign, Inédita.

Fikkert, Paula. 2005. From phonetic categories to phonological features specification: Acquiring the European Portuguese vowel system, Lingue e linguaggio, 4, 2: 263-280.

Goldsmith, John. 1976. Autosegmental Phonology. Massachusetts Institute of technology. MIT PHD Dissertation.

Ideriha, Patrícia N. e Suelly Cecília Olivan Limongi. 2007. Avaliação eletromiográfica da sucção em bebês com síndrome de Down, Revista da sociedade brasileira de Fonoaudiologia, 12, 3: 174-183.

Jakobson, Roman. 1967. Fonema e Fonologia, Rio de Janeiro, Acadêmica. 
Kent, Ray. D. e Houri K. Vorperian. 2013. Speech impairment in Down syndrome: a review, Journal of Speech and Language Learning Research, 56, 1: 178-210.

Kent, Ray D. e Charles Read. 1992. Acoustic analyses of speech, San Diego, Singular Publishing Group.

Malmberg, Bertil. 1954. A fonética: no mundo dos sons da linguagem, Lisboa, Editora Livros do Brasil.

Matzenauer, Carmen. L. B. e Ana R. M. Miranda. 2009. Traços distintivos e a aquisição das vogais do PB. Em Dermeval da Hora (ed.), Vogais no ponto mais oriental das Américas. Paraíba, Ideia: 37-55.

Maia, Eleonora Albano da Motta. 1985. No reino da fala: a linguagem e seus sons, São Paulo, Ática.

Motta, Paulo E. 1980. Genética médica, 2a . Ed., Rio de Janeiro, Guanabara Koogan.

Mustacchi, Zan e Sergio Peres. 2000. Genética baseada em evidências: síndromes e heranças, São Paulo, CID Editora.

Oliveira, Mariane Vera Pacheco. 2013. Produção vocálica: análise acústica e síndrome de Down, Diadorim, 14: 99-126.

Oliveira, Marian e Wilmar R. D. D’Ângelis. 2012. Estudo comparativo do padrão formântico da vogal /a/ produzida por sujeitos com síndrome de Down, Confluência, 1: 248-275.

Oliveira, Marian e Vera Pacheco. 2012. Características acústicas da vogal /i/ produzida por sujeitos com síndrome de Down, Veredas, 16: 104-119.

Oliveira, Marian. 2011. Sobre a produção vocálica na síndrome de Down: descrição acústica e inferências articulatórias. Tese de Doutorado, Universidade Estadual de Capinas. Campinas. Inedita.

Otto, Priscila G., Paulo A. Otto e Oswaldo Pessoa. 1998. Genética Humana e Clínica, São Paulo, Editora Roca Ltda.

Pacheco, Vera, Marian Oliveira e Priscila Ribeiro. 2013. Em busca da melodia nordestina: as vogais médias pretônicas de um dialeto baiano, Lingüística, 29, 1: 167-187.

Wetzels, Leo. 1992. Mid vowel neutralization in Brazilian Portuguese, Cadernos de Estudos Linguísticos, 1, 1: 19-55. 